\title{
Research on Teaching Reform of Architecture Basic Courses Combined with Practice
}

\author{
Wan-Fei GAO ${ }^{1, a,{ }^{*}}$, Ji-Wei ZHU ${ }^{1, b}$, Yu-Wei WANG ${ }^{1, c}$ \\ ${ }^{1,2,3} \mathrm{Xi}$ ' an University of Technology, China \\ agaowanfei@xaut.edu.cn, bxautzhu@163.com, xautwangyuwei@163.com
}

Keywords: Teaching reform, Preliminary architecture, Practice, Architecture.

\begin{abstract}
This paper states the main contents and importance of architecture basic courses, Preliminary Architecture 1, 2 and 3, and puts forward the optimizing aims and methods in view of the existing problems in traditional teaching combined with practice. It includes cultivating the design thinking and overall thinking, cultivating the design ability and training the practice ability, cultivating innovative consciousness and ability. The aims are optimizing the teaching contents, and improving the curriculum system, leading students understand the knowledge with practice, and cultivate comprehensive graduates with excellent knowledge, ability and quality.
\end{abstract}

\section{Introduction}

Architecture major and urban planning major cultivate excellent graduates who specialized in building design, urban planning, management and research, working in architectural design and planning management apartments, and have abilities to complete various kinds of design and adapt different occupations. Graduates work in institutes and apartments of architecture design, planning, research, management, government, engineering design, development and consulting, real estate, and higher education. Xi' an University of Technology started the major Urban Planning and Architecture since 2002 and 2012, with five years education, cultivated lots of excellent undergraduates. Preliminary architecture series courses are important and basic for undergraduate education. Based on the continuous revision by the specialize committee and many experts, the courses have high level teaching books and materials, and also many standardized samples for drawings. They are the primary and crucial courses lead students to the Architecture and Urban Planning major's professional fields.

\section{Contents and Importance of Architecture Basic Professional Courses}

The major Architecture and Urban Planning has main professional courses are Preliminary Architecture 1, 2, 3, set in the first three semesters. Content of Preliminary Architecture 1 is grasp the standard and method of tool drawing, and learn graphic expression of design intention. Content of Preliminary Architecture 2 is monochrome and color rendering, and learn using shade and color to show architecture and space. Content of Preliminary Architecture 3 is architectural analysis and mapping, and learn plane and stereoscopic composition to enhance the plane and space ability.

These three professional courses are crucial to the undergraduate cultivation, and is the basic training for students step into professional field. Actually students take most of their study time on preliminary architecture series courses, because these series course give them the most help for further study. There were 11 teachers in Xi' an University of Technology teach these courses independently or co-work. I undertook Preliminary Architecture 1 and 2 since 2011, and assisted Preliminary Architecture 3, fully know the teaching contents and students' learning situation. These series courses have following features.

(1) Pay attention to cultivate hand ability. These series courses focus on cultivating students' hand ability by practicing class works to enhance their proficiency of drawing presentation. (2) Pay attention to train plane and space design. By practicing kinds of drawing, model and analysis, students have basic understanding of major, and could present the space by basic methods. (3) Pay 
attention to build space thinking model. By theory teaching and practicing, students could have better three dimensional spatial perception, and easy to step into professional field.

\section{Problems Found in the Teaching Process}

After many years teaching, and observed students learning, communicated with them, I summarized some problems in the preliminary series courses for architecture and urban planning major.

\section{Training Design Thinking}

During the teaching process I discovered that some students were passively receiving teaching tasks arranged by teachers. A drawing was repeatedly drawn several dozen times but still unable to achieve satisfactory results. Some students draw very well and were able to master the method of expression certain types of drawings, but fail to have satisfactory solutions when creation. This reflects the difference between passive thinking and positive thinking, while traditional teaching often ignores the thinking cultivation. Therefore, it is very significant to find a reasonable and efficient way of transforming the passive thinking mode into positive thinking mode. It is necessary to analyze the ways of thinking when students encounter different situations in the expression, presentation and model analysis, to guide students using more reasonable thinking ways to solve design problems, and form teaching method that focuses on cultivating students' design thinking as an important content.

\section{Training Design Ability}

It is necessary to increase design ability training based on the original teaching outline. It is necessary to develop students' understanding drawings contents in the actual situation, and think of problems expressed from the drawings by observing the actual construction effects. The Preliminary Architecture 1 needs to enable students understanding the real scale and visual scales, and realize the concept of space through a simple partition plane line design. The Preliminary Architecture 2 requires a simple design of a small solid model to enable students understanding the construction of planes, facades, sections, and structures, as well as the light and dark features of objects in natural light conditions. The Preliminary Architecture 3 needs to construct a simple roof courtyard landscape, and then think about the problems expressed on the drawings, and exercise the forward and backward transformation thinking capability.

\section{Cultivating Innovative Consciousness}

During the teaching process, I found that some students' drawing skills were good but lack of creative thinking. Some of the students' space thinking and creativity were strong but could not express well. Therefore, during the learning process, some felt difficult and even had conflicted ideas and thought that they cannot complete the professional learning in future. The Engineering Training Center of Xi' an University of Technology provides a good platform for integrating the basic theory of architecture majors with practice, strengthening the students' ability of handmade activities, improving the ability of innovation. It is necessary to develop practical projects that are closely related to the curriculum so that the teaching content of the preliminary series of courses can be embodied in practice, so as to deepen students' understanding of the major and to increase interest in the profession. The practice content is used as a breakthrough to inspire students innovate consciousness.

\section{Contents and Methods of Teaching Reform Combined with Practice}

\section{Cultivate Design Thinking and Overall Thinking}

Every drawing for teaching is identified by professional education committee, after the teaching materials explanation to be used as practice models, training the drawing ability and design thinking. Students have to understand every drawing's content, which is the essential part now every teacher do. At the meantime, teachers have to tell students which stage are these drawings on in the whole 
design process, to construct their overall view. Teachers have to tell students how to solve design problems by reasonable thinking methods, guiding them to form a better thinking style. Turn the negative thinking style of following painting to positive thinking mode, to have the thinking foundation for later study on other courses and further works.

\section{Cultivate Design Ability and Practice Training}

Drawing is one of the presenting ways to real architecture and planning, and could indirectly reflect reality. During the learning of present drawings, though most students could pain it accurate and exquisite, they still could not understand the real scale and space. In this teaching reform, aims to every drawing work, we put their contents into real site, using line and wood these kinds of identifier to reproduce the real scale, to make students feel the different scale compared with paper drawings scale, and improve space understanding. We choose the roof platform of Engineering Training Center of our university, to set as Architecture and Urban Planning majors' active place. There we reproduce real scale and do some easy space construction, to improve students' drawing ability, design ability, handmade ability, analyze ability and express ability.

\section{Cultivate Creative Consciousness}

Deeply understand the paper drawing means know the changing form scope, knowing how to get more from one. On the basic requirements, students are taught to further design the rest part to have flexible design thinking and ability. During the teaching in every semester, we choose three paper drawings or models to ask students redesign, to play their own advantages to redesign. This staff sets after understanding basic form, scale and concept, before most professional courses training, so the design has high innovative features. Students have different artistic knowledge, aesthetic level, logical and spatial thinking ability, and some have natural and super strong understanding and grasp to color or curve, so let them put their different ability into these kinds of design could make them further understand and transcend themselves, which is meaningful. We got several excellent design works from these stages. Students may combine the architecture with art but more art, show us the art painting which has architecture factor in it. In real world it may not be constructed for the reason of materials or technique but it is a good design.

These all require Architecture and Urban Planning majors' teachers know much about every student, knowing their individual difference, and their advantages of all aspects, knowing how to guide different students by different ways. It is better to cultivate students' confidence personality, and encourage them to be a high quality person.

\section{Teaching Reform Achievements}

The basic courses of architecture major play an important role in the architecture undergraduates' education. With the rapid development of the construction industry process, teaching reform is particularly important. The teaching reform of the basic courses of architecture has a series of achievement: (1) Adjusted, refined and standardized the teaching plan; (2) Turned the training mode of focusing on job outcomes into developing design thinking and ability; (3) Respected individual differences and improved the traditional dogma teaching; (4) Combined teaching with practice, allowing students apply drawings to actual construction, and present their thinking in design and construction.

University Engineering and Training Center provides practical site for us, and provides various tools and materials needed for space awareness training. It is a great assistance and promotion for the practical activities of the preliminary series courses. Preliminary series courses is based on the optimal design of the person in different projects and the participants to form a small teaching program that is suitable for difficulties, could help students to connect the theory with practice effectively, and lead them to complete practical projects based on the knowledge of classroom theory and drawings.

By the implementation of a number of practical contents, improved students' thinking ability, cultivated simple construction ability, so that students can associate the drawing with actual 
construction. At the same time, improved students' creativity and innovation, enriched the landscape and ecological environment of the school engineering training center, enriched art atmosphere, and significantly promoted the cultivation of innovation.

\section{Acknowledgment}

This paper has been supported by Xi' an University of Technology Education and Teaching Reform Research Program (xqj1632) and Outstanding Engineer Education and Training Program of Education Ministry (201338).

\section{References}

[1] ZHU Jiwei, Li Zhenzhen. Talking about the effective communication between postgraduates and tutors, J. New Western (Theory), 2016(04):103-104.

[2] LIU Zhimin. Integration of production and education: from "integration" to "integration", J. China higher education, 2018(02):24-25.

[3] NING Qimeng, TANG Hui. On teaching reform for urban design of architecture major based on practical teaching, J. Shanxi architecture, 2016,42(17):241-242.

[4] GU Rong, YANG Qingqing, ZHANG Mi, ZHANG Jianyong. Optimal Design of Curriculum Structure for the Cultivation of Resolution Ability in Complex Engineering Problems, J.Higher Engineering Education Research, 2018(01):54-57+87.

[5] Li Yuqian, CaiRuilin, Chen Wanming. Construction of Integrated Production-Education Fusion Platform for Emerging Engineering-—From an incomplete contract perspective, J.China Higher Education Research, 2018(03):38-43.

[6] WANG Zhiqiang, DAI Yiping. The Principal Type and Path Choice for University - Industry Sector Cooperation in the European Union, J. International and Comparative Education, 2018, 40(02):7-12.

[7] ZHAO Bihua. How does Student-Faculty Interaction Affect College Students' Learning Outcomes - - The mediating effect of academic challenges and sense of school belonging, J.China Higher Education Research, 2018(03):61-67. 